\title{
High dorsal resection for hepatocellular carcinoma: surgical plane and outcomes
}

\author{
Shintaro Yamazaki, Tadatoshi Takayama, Masaru Aoki, Nao Yoshida, Tokio Higaki \\ Department of Digestive Surgery, Nihon University School of Medicine, Tokyo, Japan \\ Correspondence to: Tadatoshi Takayama, MD. Department of Digestive Surgery, Nihon University School of Medicine, ZIP code: 173-8610, 30-1 \\ Ohyaguchikami-machi, Itabashi-ku, Tokyo, Japan. Email: takayama.tadatoshi@nihon-u.ac.jp.
}

\begin{abstract}
High dorsal resection (HDR) of the liver is a systematic resection technique for hepatocellular carcinoma (HCC) arising in the caudate lobe. HDR is rarely performed, as the procedure requires a high level of operative skill, knowledge of liver anatomy and is performed in patients with limited hepatic function. Between 2002 and 2012, we performed HDR on 9 patients. The median operation time was $534 \mathrm{~min}$ (range, 349-903 min), and the median blood loss volume was $430 \mathrm{~mL}$ (range, 94-4,530 mL). The severe morbidity rate was $11.1 \%$, but there was no operative mortality, and the median hospitalization was 13 days (range, 8-93 days). The overall survival was 49.7 months (range, 3.1-89.0 months). Despite the hard-to-approach anatomic location, HDR can be carried out safely with good survival compared to other segments.
\end{abstract}

Keywords: Hepatocellular carcinoma (HCC); liver resection; caudate lobe

Submitted Aug 12, 2020. Accepted for publication Jan 18, 2021.

doi: 10.21037/qims-20-964

View this article at: http://dx.doi.org/10.21037/qims-20-964

\section{Introduction}

The caudate lobe is located at the most dorsal domain of the liver, and the procedure for resecting the lobe is complex. The caudate lobe is surgically classified into 3 portions with prominent landmarks: (I) Spiegel portion (left protruding part from Arantius' ligament), (II) process portion (right protruding part, caudal to the right portal pedicle), and (III) caval portion (paracaval part that is covered by the right and middle hepatic veins (MHV) and bordered on the dorsal side by the right portal pedicle). The 9 procedures for caudate lobe resection have been described (1). When the tumor is located in the paracaval portion or occupies the entire caudate lobe, it can be resected with other adjacent liver regions in patients with good liver function. When a tumor less than $5 \mathrm{~cm}$ in diameter is localized in Spiegel's lobe or the caudate process, only the portion, including the tumor, should be resected. High dorsal resection (HDR) is planned only when patients have a poor functional reserve [indocyanine green retention rate at $15 \mathrm{~min}\left(\mathrm{ICG}-\mathrm{R}_{15}\right)$
$>20 \%](2)$.

HDR enables en bloc removal of the 3 portions (Spiegel, process, and caval portions) (3) of the caudate lobe without sacrificing any other major hepatic vessels $(2,4)$. However, this procedure is technically demanding as the operation field is deep and narrow on the liver's dorsal side $(2,5,6)$. As important prerequisites, preparative total liver mobilization and exposing landmarks during liver resection are indispensable $(5,7)$. HDR is rarely performed, and the pitfalls have been insufficiently recognized. Here, we described the technical pitfalls and operative outcomes at our institution, focusing on procedural and operative perspectives.

\section{Methods}

\section{Patients}

Between September 2002 and February 2012, there were 141 patients of resection for hepatocellular carcinoma 


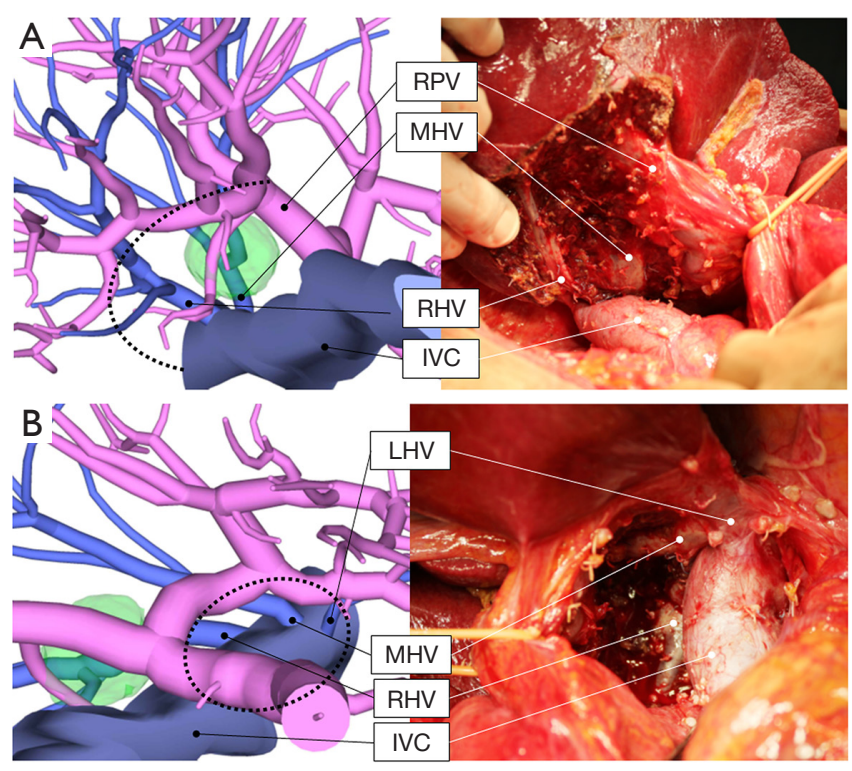

Figure 1 Surgical planes from the right and left side of high dorsal resection were visualized with main landmark structures. (A) Surgical plane from the right side. Right boundary transection line is key to having a wider operation view. Exposing the dorsal side of the right hepatic vein (RHV) is the first step. Transection continues to the right side of the inferior vena cava (IVC) via the dorsal side of the middle hepatic vein (MHV). At the hepatic hilum, thin Glissonean branches of the caudate lobe should be carefully divided. (B) Surgical plane from the left side. From the left side view, the operation field is limited because the hepatoduodenal ligament is fixed. LHV, left hepatic vein; RPV, right portal vein.

(HCC) originating in the caudate lobe. Among them, a total of 9 patients underwent HDR (Takayama's procedure) at Nihon University Itabashi Hospital (2). Surgical indications were determined according to the tumor location within the lobe and the ICG- $\mathrm{R}_{15}$. Recently, we established an algorithm to select the optimal procedure for caudate lobe HCC based on our experience (1). When HCC $(<3 \mathrm{~cm})$ is localized in the Spiegel or process portion, partial resection of each portion is indicated. In patients with large HCC $(>3 \mathrm{~cm})$ and good ICG- $\mathrm{R}_{15}(<10 \%)$, left hemihepatectomy for Spiegel-HCC or right hemihepatectomy for process$\mathrm{HCC}$ is the first procedure, and in those with ICG- $\mathrm{R}_{15}$ $\geq 10 \%$, partial resection or ventral resection is indicated (8). When HCC $(>3 \mathrm{~cm})$ is located in the caval portion, concomitant total caudate lobe with right hemihepatectomy is the first option in those with ICG- $\mathrm{R}_{15}<10 \%$. Irrespective of tumor size, ventral resection is indicated in patients with ICG- $R_{15} 10-20 \%$, and HDR is indicated in patients with
ICG-R ${ }_{15} \geq 20 \%(2,8)$.

\section{Procedure}

For HDR, the caudate lobe's right boundary and the transection line at the ventral side were hard to visualize $(2,5-7)$. Therefore, a "counterstaining technique" via the right posterior portal branch helped visualize the border between the stained and unstained area, which corresponded to that of the posterior segment and caudate process $(2,4)$. The "tattooing technique" passing through the right hepatic vein (RHV) and MHV created a landmark in the ventral border of the liver parenchyma during liver transection (4). Other boundaries of the caudate lobe were easily recognized by the corresponding vessels or structures [left border, Arantius' ligament; dorsal surface, inferior vena cava (IVC); ventral surface, the main trunk of the RHV and MHV; cranial extremity, bifurcation of the major hepatic veins; caudal extremity, hepatic hilum].

Liver transection started from the right side boundary line, which was revealed by the counterstaining method $(2,4)$ and proceeded cranially towards the posterior surface of the RHV, followed by division of the caudate posterior Glisson's branches. Creating a right-side boundary transection line is a key step to creating a good surgical plane (6) (Figure 1A). When the transection proceeded to the hepatic hilum, the Glisson's branches to the paracaval portion was divided. On the left side, Spiegel's lobe was transected along the Arantius' ligament (Figure 1B). Then, after complete resection of the caudate lobe by HDR, the ventral surface of the IVC and the dorsal surfaces of the RHV, MHV, and hepatic hilum were exposed completely on the raw surface of the liver.

\section{Results}

\section{Patient characteristics}

In the 9 patients who underwent HDR (Table 1), the median tumor diameter was $35 \mathrm{~mm}$ (range, $18-80 \mathrm{~mm}$ ), and the median ICG- $\mathrm{R}_{15}$ value was $11.6 \%$ (range, $2.3-16.1 \%$ ). One patient had a tumor larger than $50 \mathrm{~mm}$ in diameter, the presence of vascular invasion, multiple nodules during surgery, and Child-Pugh class B liver function.

\section{Outcomes of the operation}

The median operation time for HDR was 534 min (range, 
Table 1 Characteristics of patients

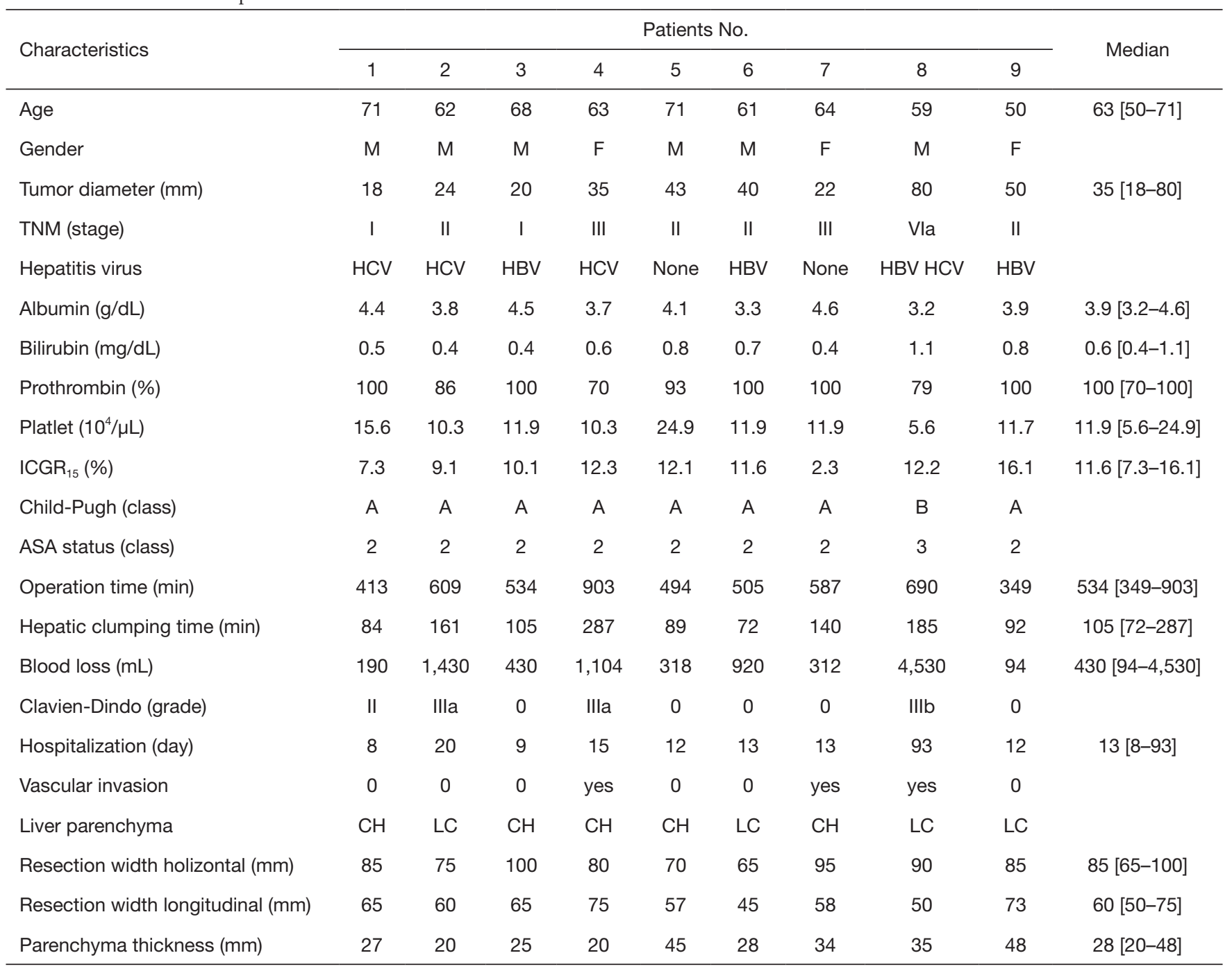

HBV, hepatitis virus $\mathrm{B}$; HCV, hepatitis virus $\mathrm{C}$; $\mathrm{ICGR}_{15}$, indocyanine green retention rate at 15 min; ASA, American Society of Anesthesiologists classification; $\mathrm{CH}$, chronic hepatitis; LC, liver cirrhosis.

349-903 $\mathrm{min}$ ), and the median intraoperative blood loss was $430 \mathrm{~mL}$ (range, 94-4,530 mL) (Table 1). One patient had a Clavien-Dindo classification grade IIIb complication [post-hepatectomy liver failure grade B according to the International Study Group of Liver Surgery (ISGLS) classification]. There was no mortality and no severe complications. The median hospitalization was 13 days (range, 8-93 days).

The median surgical margin was $0 \mathrm{~mm}$ (range, $0-3 \mathrm{~mm}$ ). The median normal parenchyma thickness at the resected specimen was $28 \mathrm{~mm}$ (range, $20-48 \mathrm{~mm}$ ). The $0 \mathrm{~mm}$ margin meant the pathological surgical margin was approximately $0 \mathrm{~mm}$, but the tumor was surrounded by a firm fibrous capsule, which is unique compared to classical HCC. The surgical impact for those tumors was comparable to R0 resection (9). Therefore, we considered the surgical margin to be $0 \mathrm{~mm}$, but not tumor exposure in such cases. Also, the caudate lobe was very narrow and located between major vessels, and when the tumor diameter was beyond the thickness of the normal parenchyma, we judged it to be the same as R0 throughout this article.

\section{Survival}

The median follow-up time was 49.0 months (range, 3.1-89.0 months). The median recurrence-free survival 


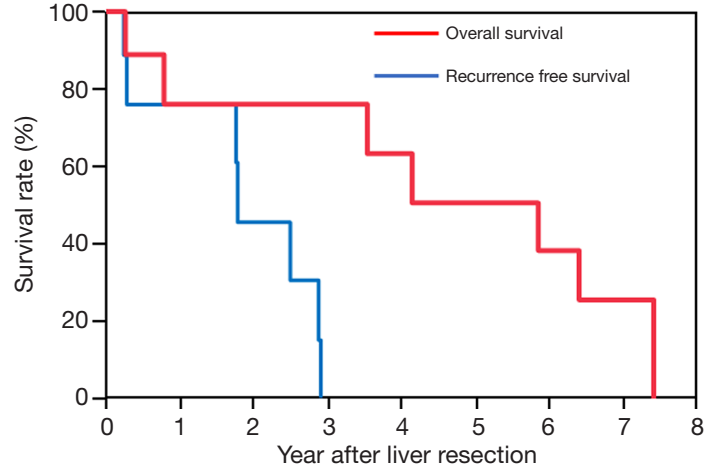

Figure 2 Survival in all participants. The median recurrence-free survival of the high dorsal resection was 21.4 months. The overall survival of the high dorsal resection was 49.7 months.

of HDR was 21.4 months (Figure 2), while the overall survival was 49.7 months. The 1 -year and 2 -year recurrence-free survival rates were $76.2 \%$ and $45.7 \%$, respectively. The 3 -year and 5 -year overall survival rates were $76.2 \%$ and $50.8 \%$, respectively.

\section{Discussion}

Even though the caudate lobe is located on the most dorsal side of the liver and is surrounded by major vessels, HDR was performed with minimum liver parenchyma loss, favorable operative safety, and comparable survival rates to that of other segments. This series performed HDR with low blood loss (median $430 \mathrm{~mL}$ ) and no mortality in patients with poor liver function. HDR achieved a comparable 5 -year-survival rate $(50.8 \%)$ to that of the entire HCC Japanese national cohort (57.3\%) (10). Since the caudate lobe is located deep inside the liver, creating a wide surgical plane contributes to liver transection safety. Therefore, exposing all landmark vessels for liver transection is essential in this specific procedure.

This study demonstrated the surgical plane and outcomes of HDR. The median parenchyma thickness at the resected specimen was only $28 \mathrm{~mm}$. The caudate lobe is surrounded by major vessels, and the hepatoduodenal ligament is located at the transection line center. The operation view of HDR is limited, especially from the left side approach. For this reason, a wide surgical view from the right anterior oblique is essential, and exposing landmark vessels is the first step $(2,5,7)$. Creating a right-side boundary line and starting transection from the right side is key to obtaining an optimal surgical plane (6). Therefore, when the tumor diameter is more than $30 \mathrm{~mm}$, the tumor is always in contact with major vessels, making it difficult to obtain a good surgical view (5-7). For that reason, the surgical margin of HDR was close to $0 \mathrm{~mm}$, but there was a fibrous capsule around the tumor. We avoided exposure of the tumor at the surgical margin by careful transection. Therefore, we recommend HDR for patients in whom caudate lobectomy with partial resection of a major lobe is precluded by poor liver function and tumor location at the paracaval portion. When the tumor is located close to the hepatic veins' junction, we advise that ventral resection is the preferred procedure (8). The operation type should be selected based on the liver functional reserve. We introduced 9 procedures for caudal lobe resection, and the selection of patients was optimal for HDR according to our algorithm (2). However, HDR requires in-depth knowledge and a high skill level for liver resection; therefore, liver transplantation is another possible option. Most of the patients in our series were within the Milan criteria, indicating that they were good candidates for liver transplantation if a donor is available.

HDR is one of the most complex liver surgery procedures as the caudate lobe is located on the most dorsal side of the liver and is surrounded by major vessels (3). Accidental bleeding from the ventral side of the major vein is the most feared complication $(5,7)$. Though the surgical view was limited, creating a good surgical plane contributes to the clearance in surgical fields. We achieved a severe grade morbidity rate of only $11.1 \%$, which is less than other reports in caudate lobe resection (26.1-60.0\%) $(4,7,11)$. The survival rate for caudate lobe HCC was thought to be worse compared to other portions. However, the reported cases' 5 -year survival rates varied, ranging from $26 \%$ to $76 \%(4,7,11)$. In our study, the 5 -year overall survival rate of $50.8 \%$ seemed reasonable, as it was comparable to the entire Japanese national study cohort for HCC (10).

In conclusion, patients with HCC of the caudate lobe with poor liver function are good candidates for HDR and can achieve good outcomes.

\section{Acknowledgments}

Funding: None.

\section{Footnote}

Conflicts of Interest: All authors have completed the ICMJE uniform disclosure form (available at http://dx.doi. org/10.21037/qims-20-964). The authors have no conflicts 
of interest to declare.

Ethical Statement: The authors are accountable for all aspects of the work in ensuring that questions related to the accuracy or integrity of any part of the work are appropriately investigated and resolved. The study was conducted in accordance with the Declaration of Helsinki (as revised in 2013). The ethics committee at Nihon University School of Medicine approved this study. The written informed consent was obtained from all patients.

Open Access Statement: This is an Open Access article distributed in accordance with the Creative Commons Attribution-NonCommercial-NoDerivs 4.0 International License (CC BY-NC-ND 4.0), which permits the noncommercial replication and distribution of the article with the strict proviso that no changes or edits are made and the original work is properly cited (including links to both the formal publication through the relevant DOI and the license). See: https://creativecommons.org/licenses/by-nc-nd/4.0/.

\section{References}

1. Takayama T, Midorikawa Y, Higaki T, Nakayama H, Moriguchi M, Aramaki O, Yamazaki S, Aoki M, Kogure K, Makuuchi M. Algorithm for Resecting Hepatocellular Carcinoma in the Caudate Lobe. Ann Surg 2019. doi: 10.1097/SLA.0000000000003384.

2. Takayama T, Tanaka T, Higaki T, Katou K, Teshima Y, Makuuchi M. High dorsal resection of the liver. J Am Coll Surg 1994;179:72-5.

3. Kumon M. Anatomical Study of the Caudate Lobe with Special Reference to Portal Venous and Biliary Branches Using Corrosion Liver Casts and Clinical Application.

Cite this article as: Yamazaki S, Takayama T, Aoki M, Yoshida N, Higaki T. High dorsal resection for hepatocellular carcinoma: surgical plane and outcomes. Quant Imaging Med Surg 2021;11(8):3792-3796. doi:10.21037/qims-20-964
Liver Cancer 2017;6:161-70.

4. Takayama T, Makuuchi M. Segmental liver resections, present and future-caudate lobe resection for liver tumors. Hepatogastroenterology 1998;45:20-3.

5. Ochiai T, Ishii H, Toma A, Ishimoto T, Yamamoto $Y$, Morimura R, Ikoma H, Otsuji E. Modified high dorsal procedure for performing isolated anatomic total caudate lobectomy (with video). World J Surg Oncol 2016;14:132.

6. Midorikawa Y, Takayama T. Caudate lobectomy (segmentectomy 1) (with video). J Hepatobiliary Pancreat Sci 2012;19:48-53.

7. Tanaka S, Shimada M, Shirabe K, Maehara S, Tsujita E, Taketomi A, Maehara Y. Surgical outcome of patients with hepatocellular carcinoma originating in the caudate lobe. Am J Surg 2005;190:451-5.

8. Higaki T, Takayama T, Midorikawa Y. Ventral approach for resecting hepatocellular carcinoma in the caval portion of the caudate lobe. Surgery 2018;163:1245-9.

9. Aoki T, Kubota K, Hasegawa K, Kubo S, Izumi N, Kokudo N, Sakamoto M, Shiina S, Takayama T, Nakashima O, Matsuyama Y, Murakami T, Kudo M; Liver Cancer Study Group of Japan. Significance of the surgical hepatic resection margin in patients with a single hepatocellular carcinoma. Br J Surg 2020;107:113-20.

10. Kudo M, Izumi N, Ichida T, Ku Y, Kokudo N, Sakamoto M, Takayama T, Nakashima O, Matsui O, Matsuyama Y. Report of the 19th follow-up survey of primary liver cancer in Japan. Hepatol Res 2016;46:372-90.

11. Liu P, Qiu BA, Bai G, Bai HW, Xia NX, Yang YX, Zhu JY, An Y, Hu B. Choice of approach for hepatectomy for hepatocellular carcinoma located in the caudate lobe: isolated or combined lobectomy? World J Gastroenterol 2012;18:3904-9. 